\title{
DEVELOPING PROFESSIONAL CREATIVE SKILLS OF FUTURE TEACHERS IN THE TECHNOLOGY FIELD OF EDUCATION ${ }^{1}$ Khushnud Yakubov, ${ }^{2}$ Anbarjon Egamova
}

${ }^{1}$ Associate Professor, Urgench State University, Urgench, Uzbekistan.,E-mail: yxushnud@mail.ru

${ }^{2}$ Lecturer, Urgench State University, Urgench, Uzbekistan.

\begin{abstract}
The ongoing renewal of educational technologies in higher education, the introduction of innovative didactics, the formation of the education, development, and personal growth systems of the future specialist within the university are faced initially with a number of intractable psychological and pedagogical problems. The most significant of them are associated with the fact that not all teachers are ready today to become the innovative personnel in their field of specialization. of innovation [1]. It is more and more obvious that the creativeness of an individual cannot be the result of mass systems and forms of education. Modern education on the verge of entering the information age can become a cultural space that will allow a person to acquire a new cultural identity. But at the same time, the world of education must change itself significantly. Determination of the personal qualities of the future teacher, the characteristics of his professional activity and progress, the formation of self-development skills is today one of the main directions of improving teacher training. The preparation of a future teacher should be built as a system of conditions for ensuring the professional and self development. It is necessary that a novice teacher theoretically and practically be able to analyze his or her own professional capabilities and, on this basis, be able to form a routine for his own further professional growth at any stage of professional activity. This can be achieved by creating a desire of future teachers.to be ready for professional self-development. A pedagogical institution needs to prepare future specialists for creative pedagogical activity, in which the acquired professional skills will be a means of developing the student's personality as well. The most important component of such training is an advanced creative imagination and the ability to evolve it. If in-depth knowledge is a platform for training a new generation of competent specialists, then creative activity is a springboard that gives them an advantage in everyday professional field, therefore, at the moment, the need to develop a technology for developing creative skills of students of the pedagogical institutions is of especial relevance.
\end{abstract}

Keywords:

Creativity, creative environment, creative activity, pedagogical innovations, active learning, trainings, development technologies, problem-based learning, research learning, project technology, innovative projects, technological education, interdisciplinary integration

Article Received: 18 October 2020, Revised: 3 November 2020, Accepted: 24 December 2020

\section{Introduction}

A significant number of studies have dealt with the problem of innovations in the education of future teachers, in which various tasks of the development and implementation of a model for the training of scientific and pedagogical personnel were solved, which is based on the synergy of scientific approaches [2], ICT acts as a means of developing innovative educational technologies [3], an innovative higher education environment is created by using the opportunities of integration processes in the field of higher education [4].

Creativity is viewed as a general ability to be creative, a certain special features of a person, which predetermines the ability to show socially significant creative activity [5]. Creativity is one of the brightest individual personality traits, a trait that determines flexible and constructive perception, thinking and human behavior [6]. Many researchers agree that the creativity is one of the important personality traits of an integrative-complex nature, which is associated with almost all of its other traits. It manifests itself at different unconscious and conscious levels, both in individual activity and in the social-role plan. Researchers have proven numerous connections of creativity with the different personality traits, arguing tha the creativity as a personal quality is reflected in all components of human behavior and activity and correlates with such individual characteristics of mental processes (thinking, perception, imagination, sensation, emotions, will, memory, attention) that contribute 
to the achievement of creative results in activities, including teaching as well from our point of view. The overwhelming majority of researchers, and ours coincides with their thought, defines creativity as a normative phenomenon inherent in everyone to a different extent, that is, one whose development can be influenced. Analysis of the literature has shown that the identification and development of this quality is carried out under the influence of different conditions that can happen by chance or be specially organized (active learning, trainings, etc.). An analysis of different concepts of creativity shows that this quality is most fully revealed and developed in the presence of favorable conditions for the creative environment: when creativity is stimulated; "deviation" in views is allowed; there is an opportunity to take risks and there is no punishment for mistakes; there is an atmosphere of trust, respect, recognition of independence, etc.

Considering the teacher's innovative activity, V.O. Slastenin and L.S. Podymova [7] distinguish creativity as one of its most important factors, necessary for creating new programs, textbooks, as well as for modifying this new at the level of implementation. Creativity is not some separate aspect of pedagogical work, but its most essential and necessary characteristic. The ability to see, pose and solve pedagogical problems in an original way, to quickly navigate situations that arise, to provide results is called pedagogical creativity.

In recent years, the number of studies on the problem of creativity has increased, which embody an integrated approach to it from the standpoint of various scientific fields. So, N.F. Vishnyakova in her work "Creative Psychopedagogy" offers her personal approach to the creative paradigm of education [8]. The trinity of the creative process, result and personality in the philosophical (creasophia), psychological (crealogy), pedagogical (creagogy) aspects and in acmeology allows a deeper understanding of the creative paradigm of education. Educational paradigm of the XXI century. is replenished with the category "creative psychological and pedagogical technology". Its essence lies in a creative approach to the pedagogical process, in which the interests and values of the individual are the dominant component of the organization and content of educational activities.[9] Creative technology of teaching is a means of changing the initial and basic positions of education, since it does not offer the solution of ready-made didactic problems, but the generation, creative formation and development of ideas, plans and projects in a wide social aspect of life. We are talking about a change in the paradigm of education: instead of a system for the formation of students who act as objects of learning, we are talking about a system that meets the educational needs of both the student and the teacher. The dominant function of education in relation to who is studying must transfer to a service function.

\section{Materials and Methods}

The methodological basis of the issues under consideration is formed by the main ideas of the doctrine of the innovative professional development of professor-teachers at higher schools[10], who follow the theory of modernization; takes into account the theoretical foundations, essence, patterns, the author's understanding of the phenomenon under study and the tendencies of its development; reproduces the principles on which the study of this problem is based (scientific nature, innovativeness, double anticipation, humanization, informatization, variability, individualization, pedagogical cocreation), provides for the interaction and relationship of scientific approaches to the study of the problem of modernization of professional training of teachers at higher educational institutions, in particular: systemic, competencebased, activity-based, synergetic, axiological, personality-oriented, and acmeological.

Firstly, a partnership in the educational process distinguishes the creative technology from the traditional. The student has the right to choose the information he needs, to determine its 
necessity. The teacher only assists the student in the learning process.

Secondly, the main condition of traditional education is changing, that is, the available, systematized knowledge must be acquired. The character of knowledge may be random and unsystematic. Their systematization, the establishment of the truth It is a student's task to systematize and establish the true individual knowledge.

Thirdly, the main element of the educational process is not knowledge, but information. The specificity of the creative technology of education bases on the possibility of developing the ability to constitute knowledge from the received information. The authors of creative technology believe that traditional methods of education are losing their effectiveness. Today, at all levels of education, more and more innovations appear - problematic, research, projective, contextual and other learning models. These models undoubtedly indicate the erosion of the foundations of classical technology and the gradual formation of a new educational paradigm, namely, creative pedagogy and psychology [9].

The fundamentals of the improvisation and renewal of higher pedagogical education, the development of theoretical and methodological foundations of the professional and pedagogical training of students are revealed in the works by A.V. Gagarin [10], N.A. Gluzman [11], E.V. Lopanova [12], G.A. Taratuta [13] and others. The above mentioned authors analyzed in detail the didactic problems caused in certain periods of development in a certain country, specific proposals and recommendations are made to improve the professional training of future and practicing teachers.

The authors who study [14] the areas of project teaching technology distinguish the following types: providing creative search and research activities of subjects of the educational process; providing activities for the development and implementation of innovative projects by teachers and students; organization of monitoring and evaluation of pedagogical projects; providing independent work and self-education. The theoretical foundations of the project technology were developed in the course of the study: the essence of the project technology, functions, principles, on the basis of which a model of the project technology of teaching was presented and determined.

The work [15] is devoted to the analysis of the system of technological training of students in foreign countries and the introduction of proposals for improving education technology in Russia. The article presents the results of the analysis of the experience of technology education in foreign countries (Germany, Great Britain, the USA, and Japan) and identifies possible ways to eliminate the shortcomings in technology education in educational institutions of Russia and to improve it in accordance with the directions of development of society, science and industry. The authors of the article proposed the solutions to the problems of training of students for technology use in Russia, taking into account the needs of the economy and the structure of education, analyzed the experience of technology education in foreign countries. The work revealed positive aspects that can be used in the preparation of students in Russia

As a result of the component-structural analysis, the components of the formation of professionalism of future teachers of higher education have been substantiated [16]: motivational-value (the formation of internal motives for achieving success in future professional activity; interest in the professional activity of a higher school teacher, the formation of the system of pedagogical values, the desire for scientific and pedagogical activity); innovative and cognitive (the formation of the system of psychological, pedagogical, methodological and technological knowledge necessary for a future teacher of higher education, striving for pedagogical innovations, innovative thinking; creativity); professional activity (readiness for 
scientific and pedagogical activity, the presence of professionally important qualities, practical and methodological skills of professional activity, the ability to model the educational process and generate new ideas, information technology competence, the ability to implement the educational process based on the latest technologies); productive-reflexive (the ability to be reflective, the need for self-development and self-actualization, the ability to self-analyze, predict the results of their activities, readiness for professional self-improvement), which constituted the basic set of criteria for determining the level of formation of the professionalism of future higher school teachers.

\section{Discussion}

Innovative processes in the higher education system are characterized by a wide range of directions for their implementation. Hereby, the most actively and meaningfully implemented innovations in the process of modernization are highlight:

1) Updating the content of technology education;

2) The personality-oriented nature of education, i.e. "Learning in collaboration", which involves the use of interactive teaching methods and technologies, including educational research and project activities;

3). formation of a single educational space;

4). the use of health-saving technologies in education;

5). the formation of students' conscious need for an objective self-assessment of their own achievements and for adequate self-realization;

6). introduction of modern information and communication technologies into the educational process [8].

All these organizational and substantive innovations require a high level of professional competence of teachers, their psychological and practical readiness for innovative activities.

It should be noted that all types of innovations are directly implemented in technological education, but there are also specific types of innovations concerning to this field only.
The educational "Technology" area is the main practice-oriented area of knowledge in a general education school, introducing students to various spheres of social production and, to the greatest extent, contributing to vocational guidance, forming moral and labor competence and education of the younger generation. This area develops and expands the integrative principle of education, laid down in the Concept of school modernization. This is actually the only school curriculum that reflects in its content the general principles of creative transformative human activity and all aspects of the material culture of mankind, providing schoolchildren with the opportunity to apply the knowledge of the fundamentals of various sciences in practice. This training course is aimed to assist students to master the skills of specific subject-transforming (and not virtual) activity, the creation of new values, which undoubtedly corresponds to the needs of the development of society. At current stage, knowledge and skills of technology that form the basis of schoolchildren's mastering the science-intensive and "advanced" technologies, which are especially important for the socioeconomic development of the country also. Moreover, the technology education contributes to the individual and civil self-realization as a person. [17]

A pedagogical higher institution needs to train future specialists for creative pedagogical activity, in which the acquired professional skills will be a means of developing the student's personality. The most important component of such training is a advanced creative imagination and the ability to develop it. If in-depth knowledge becomes a platform for training a new generation of competent specialists, then creative activity is a springboard that gives them an advantage in daily-work life. Therefore, at present, the need to advance the technology for the development of creativity of students of a pedagogical university is becoming especially relevant.

Result 
Thus, the analysis of psychological and pedagogical literature on the problem under study made it possible to conclude that creativity is a dynamic, integrative personal characteristic that determines the ability to be creative and is a condition for the professional self-development and self-realization of the future teacher.

The constantly increasing dynamism of modern education, significant changes in the motivation of labor activity - a person's turn from the search for a livelihood to an orientation towards personal self-improvement, selfrealization and creativity, the need for constant renewal and differentiation of knowledge, which is directly related to creativity, are the reasons for the growth of interest in creativity in the field of education.

It is necessary to create opportunities for personal development and creative self-realization of each student and to form his need for lifelong learning in preparing teachers of technology in the field of education. An important element in the system of professional personnel training is the formation of students' skills for independent acquisition of knowledge.

As has been noted in a number of studies [8], the ability to learn includes several types of activities, in following different purpose: a ) search for new information, the ability to navigate in the modern classification of sources; b) the ability to understand what has been read, highlighting and fixing the main thing; c) assimilation of the allocated with the help of certain types of skills.

We consider the formation of the skills of constructing model hypotheses as an obligatory element of the research process, which must be given special attention in the development of students' creative abilities. The current research substantiated that the level and depth of knowledge is in direct proportion to the student's ability to build figurative models of the objects, theories and processes under study. A correctly formed figurative model allows the student not only to deeply penetrate into the essence of the process or phenomenon under study, but also makes it possible to find different options (approaches) to solving professional problems.

To implement the task of a creative approach to solving professional problems, the structure of each lesson should include the following procedures:

1) determination of the purpose of scientific research;

2) determination of the system of selection of facts;

3) conducting an experiment in order to accumulate facts;

4) generalization of the obtained facts and the formulation of a hypothesis;

5) the consequences of experimental verification;

6) experimental verification of the hypothesis;

7) proposals for the possible implementation of the results obtained.

In the case of several (3-5) unsuccessful attempts to solve the problem, the student receives an indirect hint from the teacher, specifying the criteria and rules for selecting facts.

Any research activity involves overcoming disagreements. According to the theory by B.M. Kedrov [1], the mechanism of the creative process is represented as a chain of successive transitions from the singular to the general and from it to the generalizing. On the way to understanding the truth, a barrier arises, which is associated with the fact that the researcher's thought moves in a certain direction. The difficulty of overcoming the barrier is associated with the inability of the student to bring thinking beyond the ordinary. An important quality of a creative person is the ability to overcome the inertia of thinking, to change the course of thought. It is necessary to offer a small group of students to solve one common problem for all for the formation of skills to overcome the barrier in creative problem solving. Depending on the degree of complexity and the goal that the teacher sets when organizing the process of solving a professional problem, different time may be allotted for it (from several minutes to several days or weeks). The time allotted to complete the task depends on the student's level of preparation and the course of study. 
One of the forms of organizing the creative activity of students is laboratory work. Individual tasks during laboratory work are aimed at:

1) the formation of skills in building models of the studied processes or phenomena;

2) the formation of experimental research skills in any field;

3) the ability to unusual approach to problem solving .

For example, in practical and laboratory classes on the methodology of teaching technologies, the students can be offered to classify methods of monitoring and accounting for students' knowledge, managing cognitive activities, methods of forming basic technical and technological concepts. This approach can act as one of the methods of organizing the creative activity of students. The main methodological techniques that stimulate creative activity include:

the student's awareness of the social and practical significance of the creative activity;

activation of cognitive activity in theoretical studies, a successful combination of theory with practice when performing specific individual tasks of a creative nature;

motivating the student to creative activities together with the teacher;

involvement in independent creative and research activities at the request of representatives of educational authorities or industrial enterprises.

\section{Conclusion}

Thus, the process of forming creativity in the professional self-education of future teachers in the field of technology education can be carried out:

- in psychological, pedagogical and professionally oriented disciplines courses;

- by attracting students to scientific research of teachers;

- while performing individual assignments during the period of writing term papers, qualification work and master's theses, doing pedagogical, technological and educational research practice.
The development of professional potential, the formation of the pedagogical skills of the future teacher and the achievement of the heights of professional culture in the context of the transformation of society are considered as a continuous process that provides an adequate response to the change in the requirements of society, the educational system, the revealed unrealized level of readiness for professional activity.

On the basis of the selected approaches and pedagogical principles, the main advantages of using the system of electronic support for the educational process, professional creative selfexpression of future teachers of higher education are determined: providing complete information, eliminating duplication of the content of educational material of different courses, quality control of the development of electronic educational and methodological complexes of disciplines, timely correction of educational programs, the choice of individual training schedules and research work.

It was revealed that the majority of masters do not clearly understand the specifics of the professional activity of a teacher of a higher educational institution in the process of the ascertaining stage of the pedagogical experiment, they cannot implement innovative and multimedia technologies in their future activities; do not understand the content and structure of the professionalism of a university professor-teacher, and during the preparation process they do not focus on this; the level of formation of their professionalism is insufficient; in practical classes and seminars, professor-teachers mainly check how future specialists reproduce the learned theoretical positions; almost do not carry out purposeful and systematic work with the aim of forming innovative and multimedia technology skills of master students. [18].

\section{References}

[1] Kh.Yakubov, A. Egamova 'D. Yakubova The Recommendation for the Further Evaluation of Professional Competence of a 
University Teacher. Journal: Critical Reviews ISSN- 2394-5125 Vol. 7, Issue 5, 2020, USA. -P. 482-484. (Scopus indexed journal). https://www.skopus.com/sourceid $/ 21100920227$

[2] Gluzman N.A., Zhelnina E.V., Ivanova T.N., Akhmetzhanova G.V., Gorbacheva N.B., Yavon S.V. Educational Environment in the Information Society as an Efficient Indicator of the Provision of High Level of Design Solutions and Technologies, Advances in Intelligent Systems and Computing. - V. 1100 AISC. 2020. - P. 778-791.

[3] Batechko N.G. Synergy of Scientific Approaches in the Study of the Training of Teachers of Higher Education in magistracy // MNCO. 2013, No. 5(42). - P. 39-43.

[4] Privalov A.N., Bogatyreva Yu.I., Romanov V.A. Engineering Center as an Innovative Component of Professional Training of IT Bachelor students // Education and Science. 2019.Vol. 21.No. 7. - P. 90-112.

[5] Koprov V.M., Sapir E.V. Integration Processes in the Innovative Environment of Higher Education // Integration of education. Volume 20, Issue 3. - Tashkent. 2016, - P. 382-392 DOI: 10.15507 / 19919468.084.020.201603.382-392.

[6] Druzhinin V.N. General Ability Psychology. $\mathrm{SPb}$.: PiterKom, 1999 .-- 368 p. (Series "Masters of Psychology")

[7] Chernilevsky D.V., Morozov A.V. Creative Pedagogy and Psychology: Textbook. Manual for University students, - M.: MGTA, 2001. - 301 p.

[8] Slastenin V.A., Podymova L.S. Pedagogy: Innovative Activity. $M \quad \therefore$ IChP Magistr Publishing House, 1997. - 224 p.

[9] Vishnyakova N.F. Creative Psychopedagogy: Psychology of Creative Learning. --Minsk, 2005, -- 240 p.

[10] Litvinenko A.N., Tamarova Z.B., Barsegyan S.L. Self-Education and Creative Selfdevelopment of Future technology Teachers // Technology Education: Theory and
Practice. Materials Sci. Conf. -Ulyanovsk: USPU, 2013. - 292 p.

[11] Gagarin A.V. Professional Training of a Competitive Higher School Teacher: Problems and Promising Directions // Akmeologiya. 2012. No.4 (44). - P. 46-49.

[12] Lopanova E.V. The Main Directions of Improving the Professional and Pedagogical Training of University Teachers // Eurasian Union of Scientists. 2015. No.7-4 (16). - P. 27-33.

[13] G.A. Taratuta Theoretical Aspects of Technology for the Formation of Professional Competence // Innovations in Education, No.5, 2020. - P. 37-47.

[14] Markova S.M., Gorlova V.G. Project technology of teaching students in the conditions of professional pedagogical education // Modern problems of science and education.-2014.-No.3;

URL: http://www.scienceeducation.ru/ru/article/view?id=13572

[15] Medvedev P.N., Maliy D.V. On the Prospects for the Development of Technological Education: Analysis of Domestic and Foreign Experience // Modern Problems of Science and Education. - 2020. - No. 6 ;URL: http://www.scienceeducation.ru/ru/article/view?id=30406

[16] Batechko N.G. Synergy of scientific approaches in the study of the training of teachers of higher education in the conditions of master's degree МНКО. 2013. № 5 (42). - P. 39-43.

[17] Tamarova Z.A., Barsegyan S.L. Formation of creativity in professional self-education of future teachers Materials of the XIX International Scientific and Practical Conference on the Problems of Technological Education of Schoolchildren // Ed. Yu.L. Khotuntsev, Moscow, MSTU im. N.E. Bauman, 2013 - 314 p.

[18] Gluzman N.A., Davkush N.V., Shpitalevskaya G.R., Gorbunova N.V. Modernization of professional training of 
teachers as a strategy for the formation of their professionalism // Modern problems of science and education. - No. 6 - 2020, URL:

http://www.science-

education.ru/ru/article/view?id=30378 